\title{
Enhancing the aqueous solubility and dissolution of olanzapine using freeze-drying
}

\author{
Mudit Dixit*, Ashwini Gopalkrishna Kini, Parthasarthi Keshavarao Kulkarni
}

Department of Pharmaceutics, J.S.S College of Pharmacy, J.S.S University, Karnataka, India

\begin{abstract}
The aim of the present study was to develop an olanzapine freeze-dried tablet (FDT). The solubility and dissolution rate of poorly water-soluble olanzapine was improved by preparing a freeze-dried tablet of olanzapine using the freeze-drying technique. The FDT was prepared by dispersing the drug in an aqueous solution of highly water-soluble carrier materials consisting of gelatin, glycine, and sorbitol. The mixture was poured in to the pockets of blister packs and then was subjected to freezing and lyophilisation. The FDT was characterised by DSC, XRD and SEM and was evaluated for saturation solubility and dissolution. The samples were stored in a stability chamber to investigate their physical stability. Results obtained by DSC and X-ray were analysed and showed the crystalline state of olanzapine in FDT transformation to the amorphous state during the formation of FDT. Scanning electron microscope (SEM) results suggest reduction in olanzapine particle size. The solubility of olanzapine from the FDT was observed to be nearly four and a half times greater than the pure drug. Results obtained from dissolution studies showed that olanzapine FDT significantly improved the dissolution rate of the drug compared with the physical mixture (PM) and the pure drug. More than $90 \%$ of olanzapine in FDT dissolved within 5 minutes, compared to only $19.78 \%$ of olanzapine pure drug dissolved over the course of 60 minutes. In a stability test, the release profile of the FDT was unchanged, as compared to the freshly prepared FDT after 90 days of storing.
\end{abstract}

Uniterms: Freeze-dried tablets/development. Olanzapine/freeze-dried tablets. Olanzapine/solubility. Olanzapine/stability. Olanzapine/dissolution. Freeze-drying.

O objetivo do presente estudo foi desenvolver comprimidos liofilizados de olanzapina (FDT). A solubilidade e a taxa de dissolução da olanzapina, fracamente solúvel em água, foram melhoradas com a preparação de comprimidos liofilizados de olanzapina usando a técnica de liofilização. O FDT foi preparado por dispersão do fármaco em solução aquosa de materiais altamente solúveis em água, como gelatina, glicina e sorbitol. A mistura foi colocada em blisters e, então, submetida ao congelamento e liofilização. O FDT foi caracterizado por DSC, Difração de Raios X e microscopia eletrônica de varredura(SEM) e avaliaram-se a solubilidade de saturação e a dissolução. As amostras for5am armazenadas em câmara de estabilidade para investigar a estabilidade física. Os resultados obtidos com DSC e Raios X foram analisados e mostraram a transformação do estado cristalino da olanzepina em FDT no estado amorfo durante a formação do FDT. Os resultados da SEM sugerem a redução do tamanho das partículas de olanzapina. A solubilidade da olanzapina do FDT melhorou significativamente a taxa de dissolução do fármaco comparativamente à mistura física $(\mathrm{PM})$ e ao fármaco puro. Mais do que $90 \%$ da olanzepina no FDT dissolveu em 5 minutos, comparativamente aos 19,78\% do fármaco puro dissolvido em 60 minutos. No teste de estabilidade, o perfil de liberação da FDT mostrou-se inalterado, quando comparado com o FDT recém-preparado, após 90 dias de armazenamento.

Unitermos: Comprimidos liofilizados/desenvolvimento. Olanzapina/comprimidos liofilizados. Olanzapina/solubilidade. Olanzapina/estabalidade. Olanzapina/dissolução. Liofilização.

*Correspondence: Mudit Dixit. Department of Pharmaceutics, J.S.S College of Pharmacy, J.S.S University, Mysore-570015, Karnataka, India. E mail: muditdixit911@yahoo.com 


\section{INTRODUCTION}

Olanzapine, 2 - methy $1-4-(4-$ methy $1-$ 1-piperazinyl)-10H-thieno-[2, 3b], [1, 5] benzodiazepine is a potent antipsychotic agent. As a free base or its hydrochloride salt, olanzapine is an active ingredient of pharmaceutical preparations used in the treatment of disorders of the central nervous system. Olanzapine belong to class II category under the biopharmaceutical classification system (BCS), i.e., it is inherently highly permeable through biological membranes, but exhibits low aqueous solubility. Rate of absorption and/or extent of bioavailability for such insoluble hydrophobic drug are controlled by rate of dissolution in gastro-intestinal fluids. However, its oral bioavailability is very low, probably due to poor solubility in water and insufficient dissolution rate (Aarsland et. al., 1999; Adams et al., 1999; Almeida et al., 1998).

Currently, several approaches are widely used to fabricate rapid dissolving tablets (RDT), including lyophilisation, solid dispersion, mucoadhesive micro-particulate, direct compression, and moulding. Therefore, several solubilisation techniques have been applied and reported to enhance the aqueous solubility of poorly water-soluble drugs, therefore there is some literature available on enhancing the solubility and dissolution of olanzapine, such as Orally Disintegrating Tablets of Olanzapine 2-Hydroxypropyl- $\beta$-Cyclodextrin Inclusion Complex (Ajit et al., 2010), Characterization of Olanzapine-Solid Dispersions (Venkateskumar et al., 2011), Formulation and evaluation of Olanzapine as Orodispersible drug delivery system of Olanzapine using beta cyclodextrin and super disintegrant (Sarath et al., 2011). There are also methods available for other water insoluble drugs, such as Formation of Solid Dispersions of mefenamic acid with crospovidone (Nagabhushanam et al., 2011), and Formation of mefenamic acid capsule with sodium lauryl sulphate (Pradnya et al., 2010), The Fast-dissolving mucoadhesive micro-particulate containing piroxicam (Francesco et al. 2005). The formation of a piroxicam acid fast dissolving tablet has also been proposed (Modasiya et al., 2009; Bhupendra et al., 2010). However, in terms of sales value, sales volume and number of products available on the market, the freeze-drying (lyophilisation) method has been the most successful (Muir, 2007). The fabrication of freeze-drying RDT is based on creating a porous matrix by subliming the water from the pre-frozen aqueous formulation of the drug containing matrix forming agents and other excipients, such as preservatives, flavors and lyoprotectants (Segar, 1998). The matrix of the freeze-drying RDT consists of two components that work together to ensure the development of a successful formulation. The first component consists of water-soluble polymers, such as gelatin, dextrin, alginate and maltodextrin (Corveleyn et al., 1998; Chandrasekhar et al., 2009). This component maintains the shape and provides mechanical strength to the tablets (binder). The second constituent consists of matrix-supporting/disintegration-enhancing agents, such as sucrose and mannitol, which act by cementing the porous framework provided by the water-soluble polymer and accelerate the disintegration of the RDT (Farhan et $a l ., 2010)$. Although there is wide availability of literature describing the preparation of RDT by freeze-drying, the number of matrix-supporting/disintegration-enhancing agents used has been limited to saccharides and polyols, with the majority of the work dedicated to the inclusion of mannitol (Segar, 1998; Corveleyn et al., 1998; Farhan et al., 2010). This is primarily because the incorporation of these matrix-forming agents requires fulfillment of stringent characteristics, such as reasonable drying time and stability during freeze-drying process, as well as formation of elegant tablets with short disintegration time and adequate mechanical properties. However, a high concentration of saccharides and polyols is required to achieve these quality features (Segar, 1998; Chandrasekhar et al., 2009; Farhan et al., 2010), thus restraining their application in delivering drugs for the treatment of long-term chronic conditions, especially for children, diabetic and obese patients, due to the requirement of limited intake of saccharides and polyols. Therefore, the present study aims to develop novel excipients by investigating the feasibility of using amino acids as matrix-supporting agents (second component) for the fabrication of RDT prepared by freeze-drying, in order to produce tablets with enhanced properties and wider application to the pediatric and geriatric patient population.

In this present study to prepare olanzapine FDT, DSC, XRD, and SEM analyses were performed to determine the physicochemical properties of the FDT and then compare these properties with those of the physical mixture (PM) and pure drug, determining the saturated solubility and dissolution characteristics of olanzapine in the prepared FDT.

\section{MATERIAL AND METHODS}

\section{Material}

Olanzapine was gifted by Micro Labs, Bangalore, India. Micronised gelatin, glycine, and sorbitol were gifted by IPCA Pharmaceutical Ltd., Mumbai, India. All the water used was distilled de-ionised water. All other materials used were analytical grade. 


\section{Method}

\section{Preparation of olanzapine freeze-dried tablets}

This method consisted of the following steps: A $2 \% \mathrm{w} / \mathrm{v}$ solution of gelatin in water was prepared, by first soaking the gelatin in water until complete hydration. The hydrated gelatin was then stirred using a magnetic stirrer until a clear solution was obtained. Equal weights of glycine $(0.886 \% \mathrm{w} / \mathrm{v})$ and sorbitol $(0.886 \% \mathrm{w} / \mathrm{v})$ were added to the gelatin solution while stirring until complete dissolution. An accurately weighed amount of olanzapine powder $(2.5 \% \mathrm{w} / \mathrm{v})$ was then dispersed in the aqueous solution of gelatin, glycine, and sorbitol. The resulting suspension above was poured into a tablet blister $(1 \mathrm{ml}$ into each of the pockets), resulting in an olanzapine dose of 25 mg per tablet. The tablet blister packs, each pack containing 8 tablets, were then transferred to an ultra low freezer at $-40{ }^{\circ} \mathrm{C}$ and kept in the freezer for 24 hours. The frozen tablets were placed in a lyophiliser for 24 hours using a Freeze Dryer (IISHIN Lab. Co. Ltd. Korea) with a condenser temperature of $-40^{\circ} \mathrm{C}$ and a pressure of $7 \times 10^{-2} \mathrm{mbar}$, followed by a secondary drying at $25^{\circ} \mathrm{C}$ for 12 hours. The FDT were kept at a desiccator's room temperature until further experiment. Five blister packs containing a total of 40 tablets were produced in each run. Eight tablets were randomly selected for drug content uniformity. The mean percentage drug content was found to be $99.54 \% \pm$ $0.014 \%$.

\section{Preparation of PM}

The olanzapine was uniformly mixed with gelatin, glycine and sorbitol in the same percentage used in the FDT using a mortar and pestle. The prepared mixtures were kept in desiccators until further use.

\section{Determination of drug content}

The FDT were triturated with $10 \mathrm{~mL}$ of water and allowed to rest for 10 minutes with occasional swirling, and water was then added to produce $100 \mathrm{~mL}$. After suitable dilution, $10 \mathrm{~mL}$ of the solution were taken and filtered through a membrane filter $(0.45 \mu \mathrm{m})$, and the amount of dissolved drug was measured at $250 \mathrm{~nm}$ using the UV spectrophotometric method. Drug content was determined from a standard plot. Sampling was performed in triplicate.

\section{Differential scanning calorimetry}

A differential scanning calorimetry (DSC) study was carried out to detect possible polymorphic transition during the crystallisation process. DSC measurements were performed on a DSC DuPont 9900 differential scanning calorimeter using a thermal analyzer.
$X$-ray diffraction analysis

$\mathrm{X}$-Ray powder diffraction patterns were obtained at room temperature using a Philips X' Pert MPD diffractometer, using $\mathrm{Cu}$ as anode material and a graphite monochromator, operated at a voltage of $40 \mathrm{~mA}, 45 \mathrm{kV}$. The process parameters used were set as a scan step size of 0.0170 (2q).

\section{Scanning electron microscopy}

Scanning electron microscopic (Joel- LV-5600, USA, with magnification of 250x) photographs were obtained to identify and confirm the spherical nature and Surface topography of the crystals.

\section{Solubility studies}

Olanzapine (100 mg), its FDT, and PM equivalent to $100 \mathrm{mg}$ of olanzapine were placed in glass stopper flasks and then shaken in a water bath at $37^{\circ} \mathrm{C}$ for 48 hours. The solutions were filtered through a membrane filter $(0.45 \mu \mathrm{g})$ and the dissolved drug was then measured spectrophotometrically at $250 \mathrm{~nm}$. Each sample was done in triplicate.

\section{Dissolution studies}

The dissolution profile of pure olanzapine compared with the PM and FDT were determined by using a USP dissolution apparatus XXIV-Type II (Electro Lab, Mumbai). All tests were conducted in $900 \mathrm{ml}$ of distilled water maintained at $37 \pm 0.2^{\circ} \mathrm{C}$ with a paddle rotation speed of $100 \mathrm{rpm}$. After specified time intervals, samples of dissolution medium were withdrawn and replaced with an equal amount of fresh medium to maintain sink conditions and then filtered. The amount of dissolved drug was determined using a UV spectrophotometric method (UV 1601 A Shimadzu, Japan) at $250 \mathrm{~nm}$ (Venkateskumar et al., 2011). Each sample was done in triplicate.

\section{Determination of physical stability}

To determine the physical stability of the FDT, tablets were placed in a climate chamber at $20^{\circ} \mathrm{C}$ with $45 \%$ of relative humidity (RH). After 90 days, the drug release percentage of olanzapine in the FDT sample was determined by a dissolution study and compared to freshly prepared FDT.

\section{RESULTS AND DISCUSSIONS}

In the preparation of olanzapine FDT, different fast-dissolving carrier materials were used. Among them, glycine was used to prevent shrinkage of the tablet during manufacturing, possibly due to the plasticising effect of lysine. This is in line with previously reported research, 
which has shown that, in freeze-dried systems, inclusion of solutes within the formulation results in lowering of the glass transition temperature and is dependent on the interactions between the added excipient and unfrozen water. Sorbitol, used to impart crystallinity, hardness, and elegance to the tablet, is a well-known and acceptable material for use in preparing freeze-dried tablets. The percentage of excipients used was optimised during the formulation process to result in a strong and elegant tablet that could be handled with ease (Farhan et al., 2010).

Figure 1 shows the DSC curves obtained for pure olanzapine, PM, and FDT. The DSC analysis was carried out to evaluate the crystalline properties of olanzapine in FDT, PM, and in the pure drug, In the DSC curve, pure olanzapine had a sharp endothermic peak at $194^{\circ} \mathrm{C}$, which corresponded to the melting point of olanzapine (Ajit et al., 2010). The thermogram of the PM showed the endothermic peak of olanzapine, although broader, spitted, and slightly shifted to the left, thus indicating that the crystalline state is maintained but decreased in the PM, and it also showed a sharp endothermic peak at $193^{\circ} \mathrm{C}$. However, the melting endotherm was absent on the DSC thermogram for the FDT, suggesting absence of crystallinity and presence of an amorphous state of the drug. This could be because olanzapine was molecularly or amorphously dispersed in the freeze-dried tablet (FDT).

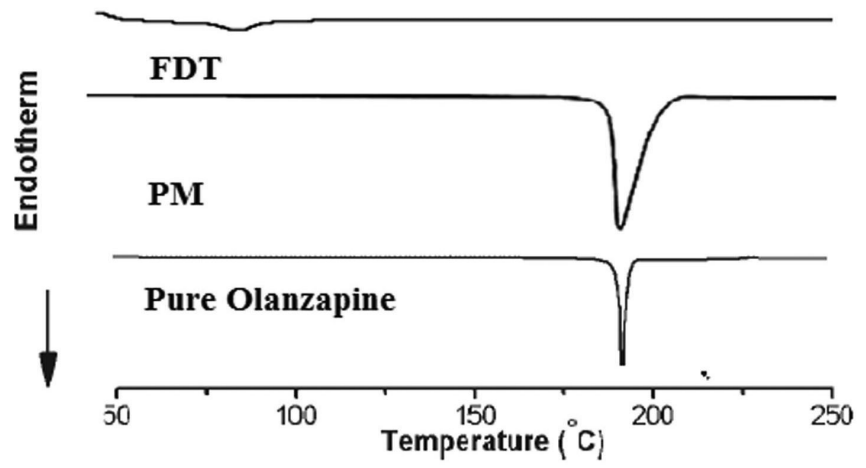

FIGURE 1 - DSC spectrum of Olanzapine samples.

X-Ray diffraction was used to analyze potential changes in the inner structure of olanzapine nanocrystals during the formulation of the FDT. The extent of such changes depends on the chemical nature and physical hardness of the active ingredient. The powder X-ray diffraction patterns of the pure drug, PM, and FDT are shown in Figure 2. The results of the DSC were further conformed by X-ray diffraction studies (Figure 2). The characteristic peak of the olanzapine appeared in the $2 \theta$ range of $10-30^{\circ}$, thus indicating that the unprocessed olanzapine was a crystalline material (Ajit et al., 2010). The pure drug exhibits

\section{FDT}

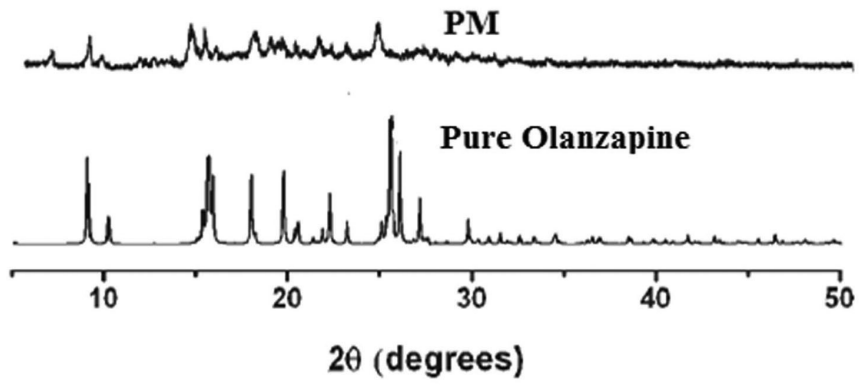

FIGURE 2 - X-ray powder diffraction spectrum of Olanzapine samples.

its characteristic diffraction peaks at various diffraction angles, thus indicating the presence of crystallinity. The X-ray diffraction study of the drug and excipients PM showed the peak corresponding to the crystalline drug molecules present in the mixture, although their intensity was lower due to the high excipients-drug ratio employed. The diffraction pattern of the drug FDT showed absence, broadening and reduction of major olanzapine diffraction peaks, thus indicating that the FDT contained mostly an amorphous form (disordered state). These results could explain the observed enhancement of solubility and rapid dissolution of olanzapine in FDT.

Scanning electron microscope (SEM) micrographs of pure olanzapine, PM, and FDT are shown in Figure 3. Results showed that olanzapine crystals could be seen in the PM, while the micrograph of FDT shows a matrix in which no crystals of olanzapine could be seen. The SEM micrograph of FDT suggests that the particles of the drug might have been reduced during dissolution in the gelatin-

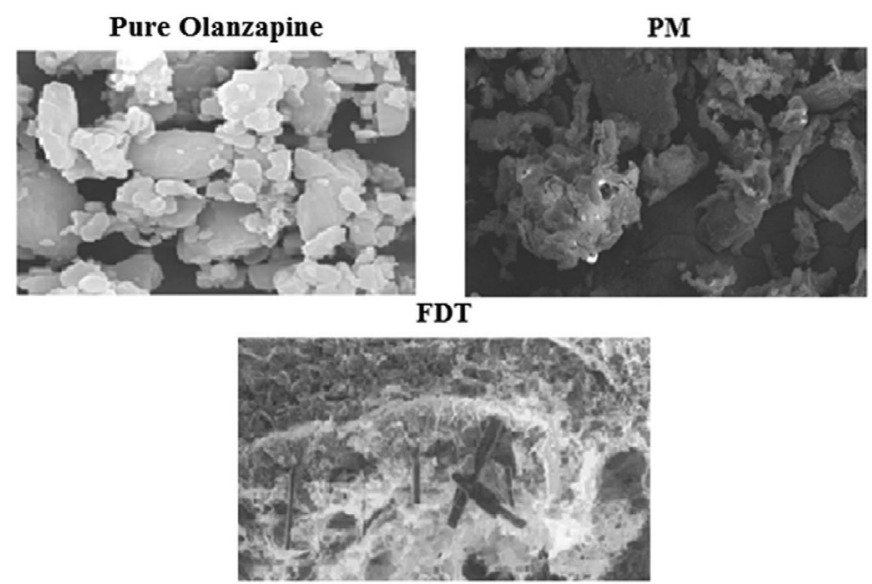

FIGURE 3 - Scanning electron micrographs of Olanzapine samples. 
glycine-sorbitol solution. This could, therefore, indicate that olanzapine particle size has been reduced, which also accelerates solubility and dissolution.

Increase in the solubility of olanzapine from FDT $(0.1283 \mathrm{mg} / \mathrm{mL})$ was found to be nearly four times higher than the solubility of the pure drug $(0.0343 \mathrm{mg} / \mathrm{mL})$, suggesting the presence of a high amount of an amorphous form of olanzapine in the FDT, indicating super-saturation obtained from the FDT. Increase in the solubility of olanzapine from the PM $(0.0831 \mathrm{mg} / \mathrm{mL})$ was more than two times that of the pure drug. This could be due to the solubilising effect of highly water-soluble carrier materials used in the formulation, such as glycine and sorbitol. The solubility results for the different formulations are shown in Table I. The higher solubility of olanzapine from FDT may be due to the increased surface area, wettability and solubilising effect of highly water-soluble carrier materials used in the formulations.

TABLE I - Solubility of olanzapine as pure drug, PM and FDT in distilled water at $37^{\circ} \mathrm{C}$

\begin{tabular}{cc}
\hline $\begin{array}{c}\text { Olanzapine samples } \\
(\mathrm{mg} / \mathrm{mL})\end{array}$ & $\begin{array}{c}\text { Solubility } \mathrm{mg} / \mathrm{mL} \\
( \pm \mathrm{SD}, \mathrm{n}=3)\end{array}$ \\
\hline Pure olanzapine & $0.0343 \pm 0.011$ \\
PM & $0.0831 \pm 0.015$ \\
FDT & $0.1283 \pm 0.013$ \\
\hline
\end{tabular}

The dissolution curves of olanzapine in distilled water are shown in Figure 4. The dissolution rate profiles were plotted as the percentage release from the FDT, PM, and pure olanzapine versus time in minutes. The rate of dissolution of pure olanzapine was slow, compared to that of PM and FDT. Olanzapine in the FDT was immediately dispersed and almost completely dissolved (95.37\%) in 5 minutes. Initial dissolution rate of olanzapine in the FDT

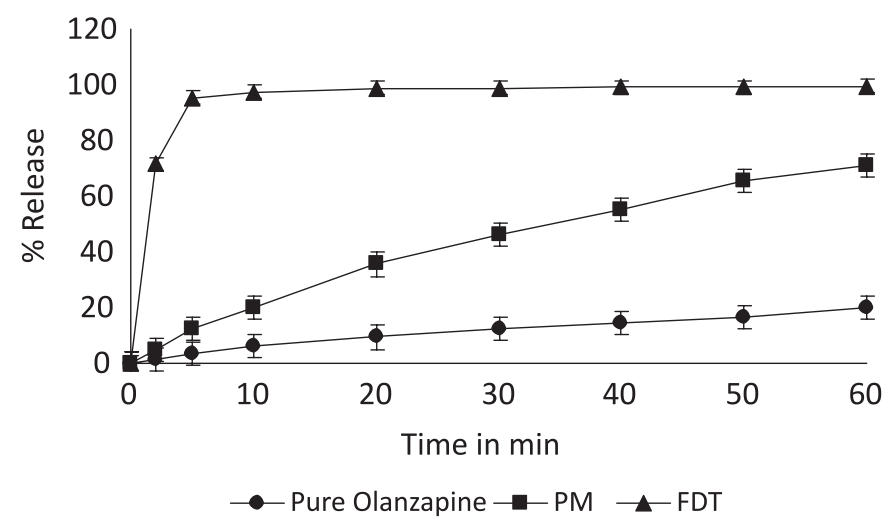

FIGURE 4 - Dissolution profiles for olanzapine as pure drug, $\mathrm{PM}$ and FDT in distilled water at $37^{\circ} \mathrm{C}$. increased markedly about twenty-one-fold in 5 minutes, compared to that of pure olanzapine. The dissolution rate was also higher and faster in FDT than in PM. The percentage of olanzapine dissolved from the PM in 60 minutes (70.83 \%) increased approximately four-fold, when compared to pure olanzapine alone $(19.78 \%)$.

Enhancement in the solubility and dissolution rates of olanzapine FDT may be attributed to the formation of an amorphous state of fast dissolving carrier materials in the FDT (Farhan et al., 2010).

The dissolution behavior of olanzapine FDT must remain unchanged during storage. The best way to guarantee this is by maintaining their physical state and molecular structure. For optimal stability of amorphous FDT, molecular mobility should be as low as possible. However, partially or fully amorphous FDT are thermodynamically unstable and will have a natural tendency to crystallise, because the crystalline state has lower energy, when compared to amorphous material. However, amorphous material can be kinetically stable, which implies that the equilibrium state, i.e. crystalline, is not reached within the timeframe of the experiment or shelf life of the product. Therefore, the physical state should be monitored, because changes therein are likely to alter drug release (Crowe et al., 2000) and this can also be monitored by determining the crystallinity percentage in the samples, by means of DSC (Nazik et al., 2010).

The results of the stability study for FDT stored at $20^{\circ} \mathrm{C}$ with $45 \%$ of RH for 90 days are shown in Figure 5. The influence of FDT on the physical stability of olanzapine was investigated. The percentage of drug release from FDT was almost the same (99.54\%) after 90 days of storage, when compared to freshly prepared FDT $(99.62 \%)$

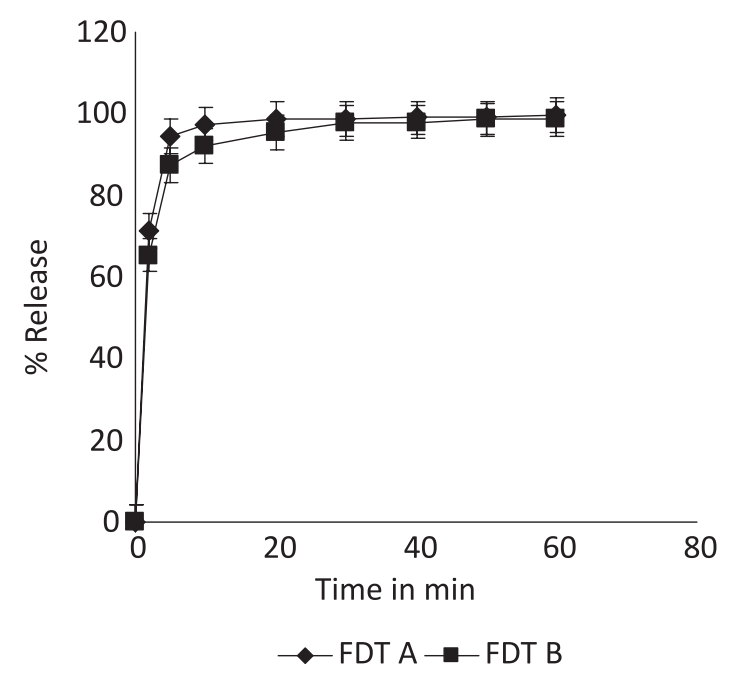

FIGURE 5 - Stability dissolution profiles of olanzapine samples. FDT A - Fresh FDT; FDT B - FDT after 90 days of storage. 
after 60 minutes. The results above showed that olanzapine FDT was stable after 90 days of storage at $20^{\circ} \mathrm{C}$ with $45 \%$ of $\mathrm{RH}$

The DSC study for physical stability revealed the crystalline and amorphous state of the drug in the FDT (Figure 6). As no change in the DSC thermograph was observed during the storage period, the DSC study could provide sufficient evidence to support that there was no change in the amorphous form of the drug in the FDT.

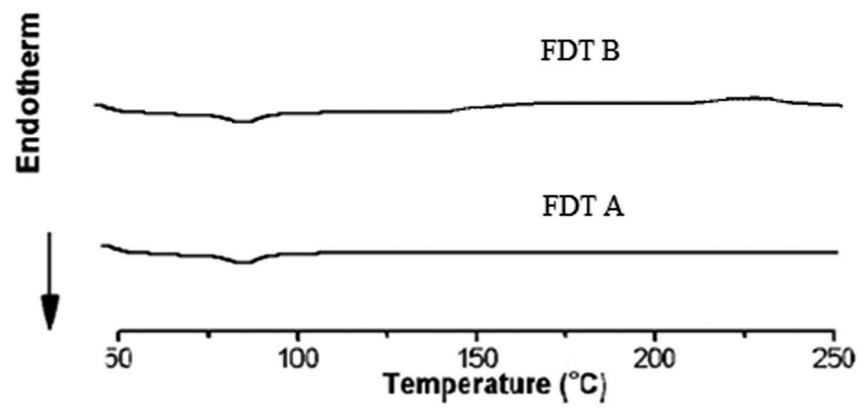

FIGURE 6 - DSC spectrum of Olanzapine samples. FDT A: fresh DFDT; FDT B: FDT after 90 days of storage.

\section{CONCLUSION}

This present study revealed that the successful formulation of olanzapine FDT made with widely used, safe, water-soluble excipients is feasible for enhancing the solubility and dissolution rate of olanzapine. Since the results obtained were attributed to the formation of an amorphous state of the olanzapine FDT and probability to reduction of the olanzapine particle size. The physical stability results for the FDT showed that the FDT was stable, and release from the FDT was almost unchanged after 90 days. Based on these results, it can be concluded that the olanzapine FDT could be suitable in terms of solubility and dissolution in water. This technique provides a promising manufacturing procedure for the formulation of olanzapine tablets by direct compression with directly compressible tablet excipients, without mixing or formulation steps. Moreover, the properties of the tablet are suitable for enhancing bioavailability.

\section{ACKNOWLEDGEMENTS}

The authors are thankful to Micro Labs, in Mumbai, India, for the gift samples of olanzapine and to the IPCA lab, Mumbai, for the gift sample of micronised gelatin, glycine, and sorbitol, as well as to the Principal, J.S.S.College of Pharmacy, Mysore, for providing the facilities to carry out this work.

\section{REFERENCES}

AARSLAND, D.; LARSEN, J.P.; LIM, N.G. Olanzapine for psychosis in patients with Parkinson's disease with and without dementia. J. Neur. Clin. Neurosci., v.11, p.392394, 1999.

ADAMS, B.B.; MUTASIM, D.F. Pustular eruption induced by olanzapine, a novel antipsychotic agent. J. Am. Acad. Derma., v.41, p.851-853, 1999.

AJIT, S.K.; GHADGE, D.M.; KOKATE, P.B. Formulation and In-vitro evaluation of orally disintegrating tablets of olanzapine-2-hydroxypropyl- $\beta$-cyclodextrin inclusion complex Iranian J. Pharm. Res., v.9, p.335-347, 2010.

ALMEIDA, O.P. Olanzapine for the treatment of tardive dyskinesia (letter). J. Clin. Psychi., v.49, p.380-381, 1998.

BHUPENDRA, G.P.; BHASKAR, P. Formulation, evaluation and optimization of orally disintegrating tablet of piroxicam. Int. J. Pharm. Tech. Res., v.2, p.1893-1899, 2010.

CORVELEYN, S.; REMON, J. Formulation of a lyophilised dry emulsion tablet for the delivery of poorly soluble drugs. Int. J. Pharm., v.166, p.65-74, 1998.

CHANDRASEKHAR, R.; HASSAN, Z.; AL-HUSBAN, F.; SMITH, A.; MOHAMMED, A. The role of formulation excipients in the development of lyophilised fastdisintegrating tablets. Eur. J. Pharm. Biopharm., v.72, p.119-129, 2009.

FRANCESCO, C.; FRANCESCA, S.; PAOLA, M.; ISABELLA, R.; FRANCESCO, D. Fast-dissolving mucoadhesive microparticulate delivery system containing piroxicam. Eur. J. Pharm. Sci., v.24, p.355-361, 2005.

FARHAN, A.H.; YVONNE, P.; AFZAL, R.M. Formulation and characterisation of lyophilised rapid disintegrating tablets using amino acids as matrix forming agents. Eur. J. Pharm. Biopharm., v.75, p.254-262, 2010.

MODASIYA, M.K.; LALA, I.I.; PRAJAPATI, B.G.; PATEL, V.M.; SHAH, D.A. Design and Characterization of Fast Disintegrating Tablets of Piroxicam. Int. J. Pharm. Tech. Res., v.1, p.353-357, 2009. 
MUIR, I. Growing sales and new opportunities for oral fast dissolve. Oral delivery: when you find the Holy Grail. Drug delivery., When You Find the Holy Grail., Available at: $<$ http://www.ondrugdelivery.com/publications/Oral_Drug _ Delivery_07.pdf $>$.Accessed: 17 nov. 2008.

NAGABHUSHANAM, M.N.; SUDHA, R.A. Dissolution enhancement of mefenamic acid using solid dispersions in crospovidone. Int. J. Pharm. Pharm., Sci., v.3, p.16-19, 2011.

NAZIK, E.; KADRIA, E.; ABDALLAH, M.; AHMED, E. Lyophilization monophase solution technique for improvement of the physicochemical properties of an anticancer drug, flutamide. Eur. J. Pharm. Biopharm., v.74, p.397-405, 2010.

PRADNYA, B.P.; GUPTA, R.M.; UDUPI, R.H.; SRIKANTH, K.; PRASAD, B.S. Development of dissolution medium for poorly water soluble drug mefenamic acid. Res. J. Biosci., v.1, n.4, p.544-549, 2010.
SARATH, C.I.; NARAYANAN, V.; SUSHMA, S. Formulation and evaluation of olanzapine as "orodispersible drug delivery system" by using beta cyclodextrin and super disintegrant. Int. J. Pharm. Sci. Res., v.2, p.1212-1216, 2011.

SEGAR, H. Drug delivery products and the Zydis fast dissolving dosage. J. Pharm. Pharmacol., v.50, p.375-383, 1998.

VENKATESKUMAR, K.; ARUNKUMAR, N.; PRIYA, R.P.V.; SIVA, P.; NEEMA, G.; PUNITHA, K. Characterization of Olanzapine-Solid Dispersions. Iranian J. Pharm. Res., v.10 p.13-24, 2011.

CROWE, J.; CROWE, L. Preservation of mammalian cellslearning nature's tricks. Nat. Biotechnol., v.18, p.145-147, 2000.

Received for publication on $02^{\text {nd }}$ March 2011 Accepted for publication on $21^{\text {st }}$ June 2011 
